\title{
PORNOGRAFIA NA INTERNET
}

\author{
MARCELO DE LUCA MARZOCHI*
}

\author{
1. Sexo - 2. Pornografia - 3. Pornografia Infantil e Pedofilia - \\ Conclusão
}

\section{Resumo}

Sexo é o assunto mais popular em qualquer tipo de mídia e com a Internet não seria diferente. Mas a rede trouxe também facilidade para a circulação da pornografia. Mas o que pornografia? É um meio de expressão que tem sua liberdade garantida como outro qualquer, desde que não seja ou não se torne ilegal. A pedofilia é o fato mais preocupante. Não se pode reduzir a pedofilia ao ato em si, nem tampouco esquecer da dimensão penal do fato, por causa da violência praticada. $O$ pedófilo precisa de médico, não de cadeia. Entretanto, aquele que simplesmente troca fotos de pornografia infantil pela Internet não deve ser tratado da mesma maneira daquele que abusa e explora sexualmente a criança. $\mathrm{O}$ art. 241 da lei $8.069 / 90$ (Estatuto da criança e do Adolescente) iguala duas condutas distintas. A conduta de fotografar é mais grave, pois pressupõe a exploração sexual do menor, a realização efetiva do ato para produção do material, enquanto que publicar consiste em disponibilizar algo já realizado. Nem sempre quem publica é o mesmo que fotografa. Na maior parte das vezes, aquele que publica ou transaciona fotos utiliza material produzido por terceiros.

Palavras-chave: Pornografia. Internet. Sexo. Abuso Sexual. Pedofilia. Crime. Estatuto da Criança e Adolescente.

\section{Abstract}

Sex is the most popular subject in any kind of media, and with Internet it wouldn't be diferent. So, the Net become very easy the circulation of pornography. But, what

* Autor do livro "direito.br - Aspectos Jurídicos da Internet no Brasil" publicado pela Editora LTR. E-mail: marcelomarzochi@globo.com. 
is pornography? It's a free way of expression, since it doesn't be or become ilegal. The pedophilia is the most worrying fact. We can't reduce pedophilia to the conduct itself, nor forget the penalty for that, because the violence was practice. The pedophile needs a doctor, not the jail. The Act 8069/90, in the article 241, consider equal the actions of to photograph and to publish. However, the first is more dangerous than the second, because the sexual abuse happens in the production of the pornographic material, when occurs the efective damage to the child, while who publish just use what was already done by others. Who published isn't necessarily the same who produced the material, took the pictures.

Keywords: Pornography. Internet. Sex. Sexual abuse. Pedophilia. Crime. Act $8.069 / 90$.

\section{$1-$ Sexo}

Sexo é o assunto mais popular não só na Internet, mas em todo tipo de mídia. Em novembro de 2000 , uma decisão judicial proibiu a participação de menores de idade na novela "Laços de Família" da Rede Globo de Televisão por causa das cenas de sexo e violência (WERNECK, 2000) (COMIM, 2000).

Segundo Carlos Eduardo Novaes e César Lobo (NOVAES; LOBO, 1997), a sociedade, como forma de controlar o desejo sexual, algo instintivo e biológico, foi deslocando o sexo do plano natural para o cultural, submetendo-o às regras e governos. Essa passagem para o plano cultural se deu com a proibição do incesto. A condenação do sexo veio com a Igreja, que evoluiu da total proibição, por causa do pecado original de Adão e Eva, à permissão desde que fosse heterossexual e orientado para reprodução. Enquanto no Ocidente ocorre a repressão da Igreja, nas culturas orientais, como China e Índia, o sexo é considerado o caminho para o paraíso.

Ainda segundo os autores, o sexo sai da clandestinidade no século $\mathrm{XX}$, com Freud e a psicanálise. Passamos da "moral vitoriana" para a liberdade sexual. Surge o movimento feminista, a pílula e a consciência da independência sexual que a mulher passa a ter. Toda essa revolução sexual encontra um grande obstáculo na década de oitenta com o surgimento da AIDS.

Entretanto, o surgimento dessa nova e mortal doença não tornou o comportamento sexual precavido e ajustado aos novos tempos. Estudos recentes mostram que no Brasil aumentou o número de casos de doenças sexualmente transmissíveis, não apenas AIDS, mas doenças cuja cura é conhecida a mais de cinquienta anos, como sífilis e gonorréia.

\section{2 - Pornografia}

A indústria da pornografia, também chamada de "entretenimento adulto", movimenta milhões em todo o mundo. Chega a ser uma indústria mais lucrativa que tráfico de drogas e de armas. Não apenas com profissionais estabelecidos, mas 
também com amadores, que se utilizam das facilidades proporcionadas pelas novas tecnologias.

Walter Maierovitch (MAIEROVITCH, 2002) mostra dados que impressionam. Nos Estados Unidos, na classe média, trezentos mil menores de dezoito anos se prostituem para satisfação do impulso consumista: comprar roupas de grife, carros, telefone celular etc. $O$ preço médio de cada programa sai por oitenta dólares e o cliente acaba virando freguês fixo ou um multiplicador que espalha aos amigos os detalhes, fornecendo o telefone para contato. Muitas jovens prostitutas nos Estados Unidos chegam a ganhar de quinhentos a seiscentos dólares por noite, sendo que as clandestinas ficam com vinte e cinco e as demais com não mais que cem dólares, segundo dados da ECPAT (End Child Prostitution in Asia Tourism, organização não-governamental criada em 1991 na Tailândia). A maior parte do dinheiro fica com o crime organizado que garante o ponto, a freguesia e dá proteção. Segundo o autor, a miséria, a fome e a falência do modelo econômico neoliberal alavancaram esse mercado. Estima-se com a pedofilia, uma das vertentes de exploração sexual, um faturamento de cinco bilhões de dólares por ano, sem contar o lucro com fotos, Internet e revistas. Só o mercado de vídeo de pedofilia gera-se anualmente 280 milhões de dólares. Na Internet estima-se a exibição de doze milhões de crianças entre dez e doze anos. $\mathrm{O}$ autor explica que na Europa as estatísticas sobre menores vitimados são separadas em três áreas, entre as quais pode haver interligação: tráfico (imigração clandestina), trabalho escravo e desfrutamento sexual (prostituição adulta, infantil e pedofilia). Cita também recente estudo da ECPAT que mostra um preocupante crescimento do tráfico de menores do Leste Europeu, para exploração sexual.

Ana Luísa Vieira (VIEIRA, 2002) afirma que, segundo a ONU, algumas das razões da exploração sexual no Brasil, que agora se expande para a Internet, são pobreza, discriminação, crime organizado, comércio de drogas. O diferencial do meio eletrônico é a possibilidade de vigilância e controle, principalmente pela memória dos acessos guardada pelos provedores nos arquivos log, os quais permitem o rastreamento de um site.

Pornografia vem do grego pornographos, que significa escritos sobre prostitutas, originalmente, referência à vida, costumes e hábitos das prostitutas e clientes. O Dicionário Michaelis conceitua pornografia como arte ou literatura obscena, tratado acerca da prostituição, coleção de pinturas ou gravuras obscenas, caráter obsceno de uma publicação, devassidão. O Dicionário Aurélio traz como uma das definições figura, fotografia, filme, espetáculo, obra literária ou de arte, relativos a, ou que tratam de coisas ou assuntos obscenos ou licenciosos, capazes de motivar ou explorar o lado sexual do indivíduo!

1 Em inglês, pornografia é conceituada como descrever ou mostrar pessoas nuas ou atos sexuais com o objetivo de causar excitação. No original: " the describing or showing of naked people or sexual acts in order to cause sexual excitement". Oxford Advanced Learner's Dictionary. Oxford University Press, 1995.

Em espanhol, pornografia é conceituada como obscenidade, narrações ou imagens de tipo erótico com finalidade comercial e sem qualquer pretensão científica ou artística. No original: "Obscenidad. 
De acordo com Eliane Moraes e Sandra Lapeiz (MORAES; LAPEIZ, 1985) a pornografia existe desde a Antigüidade. Na Bíblia há várias passagens, referindo-se principalmente à prostituição. Na Grécia o sexo era cultuado, principalmente na literatura com temas como prostituição e incesto. Na pintura e escultura também se encontram representações de cena eróticas, com destaque ao coito anal e símbolos fálicos. A homossexualidade era comum entre os gregos. Dildos - pênis artificiais - eram produto de exportação de Mileto. No Oriente temos o Kama Sutra, de Vatsayana, um estudo detalhado o amor e o prazer sexual. No Império Romano começa o interesse pelas formas mórbidas de prazer, como o sadismo e a flagelação. Esse interesse pelo castigo físico, que se estende pela Idade Média, se deve à moral católica, como forma de reprimir o desejo sexual. Os castigos antes aplicados nas costas e ombros foram transferidos para partes baixas do corpo, como as nádegas, por exemplo, por medo que os danos se tornasse irreversíveis. Acabou se transformando em mais uma forma de prazer.

Segundo as autoras, a popularização da pornografia se dá com o Marquês de Sade, pela perversão, devassidão e libertinagem. O principal crime do Marquês foi o estupro de uma mulher a quem açoitou com um ramo de árvore, fazendo cortes no corpo dela com um canivete e colocando cera nas feridas. Há ainda Leopold Von Sacher-Masoch, o Barão Sacher-Masoch, criador do masoquismo, destacado em seus livros por causa da atração pela crueldade. No século XIX há uma disseminação do erotismo, com publicações clandestinas, na moda e na fotografia, com o destaque dado ao corpo feminino. No século XX, com o avanço tecnológico - fotografia e cinema no início, televisão a partir da década de 50 e Internet e meios digitais de comunicação na de 90 - ocorre uma explosão do erotismo, principalmente a partir dos anos 60 com a revolução sexual.

Segundo as autoras:

(...) A pornografia é consumida. Mesmo sendo produzida para consumo, não pode ser considerada um produto comum. (...) Ao ser consumida ela aciona um mecanismo todo particular do ser humano: a fantasia. Apesar de todo esforço das sociedades de massa em direção à homogeneização da sexualidade, podemos supor que cada indivíduo possa se relacionar de modo singular com o material pornográfico. Essa relação consumidor/produto, ou imaginação individual/pornografia, se inscreve no universo do proibido, ou mais especificamente, essa relação vai passar pela forma particular que cada pessoa tem de digerir as proibições, de transgredir. (...) A proibição existe para ser violada. Esse é o ponto de partida dessa reflexão. Por isso, o proibido pressupõe sempre a sua contrapartida oposta e inseparável: a transgressão. (...) A prática do proibido só é possível na forma de transgressão e é isso que alimenta e impulsiona a nossa vida sexual. É isso que vai dar o colorido singular que nós chamamos de desejo.

Lecturas, narraciones o imagenes de tipo erótico com fin comercial y al margen de cualquier pretensión científica o artística". Diccionario básico de la lengua española. Sociedad Española de Libreria, 1996. 
A mulher era considerada na Antigüidade como o símbolo do desejo sexual, mito reforçado pelo cristianismo, com Eva seduzindo Adão e dando origem ao pecado original. No século XVIII, com o surgimento da classe média nasce o mito da mulher como anjo doméstico (BORGES, 2000). A percepção da mulher como objeto continua até os dias atuais, difundida através da mídia a qual trata meninas como adultas pelo culto à beleza física e à sedução, como um produto a ser consumido (MIGLIACCIO, 2001).

Sobre pornografia há uma decisão do Supremo Tribunal Federal:

BRASIL, Supremo Tribunal Federal, Recurso em Mandado de Segurança: RMS-18534, Segunda Turma, Relator: Ministro Aliomar Baleeiro, 1.10.1968. Obscenidade e pornografia. O direito constitucional de livre manifestação do pensamento não exclui a punição penal, nem a repressão administrativa de material impresso, fotografado, irradiado ou divulgado por qualquer meio, para divulgação pornográfica ou obscena, nos termos e forma da lei. À falta de conceito legal do que é pornográfico, obsceno ou contrário aos bons costumes, a autoridade deverá guiar-se pela consciência de homem médio de seu tempo, perscrutando os propósitos dos autores do material suspeito, notadamente a ausência, neles, de qualquer valor literário, artístico, educacional ou científico que o redima de seus aspectos mais crus e chocantes. A apreensão de periódicos obscenos cometida ao Juiz de Menores pela Lei de Imprensa visa à proteção de crianças e adolescentes contra o que é impróprio à sua formação moral e psicológica, o que não importa em vedação absoluta do acesso de adultos que os queiram ler. Nesse sentido, o Juiz poderá adotar medidas razoáveis que impeçam a venda aos menores até o limite de idade que julgar conveniente, desses materiais, ou a consulta dos mesmos por parte deles.

Germaine Greer (GREER, 2000) diz o seguinte sobre pornografia:

A pornografia ilícita é a desbravadora. Onde ela vai, a mídia legítima precisa ir atrás se não quiser deixar para os inescrupulosos a parte do leão dos lucros, e finalmente, o negócio todo. Se os filmes cults conseguem gerar, por uma bagatela, o tipo de interesse da mídia que custa milhões aos filmes normais, estes vão copiá-los - lenta, mas inevitavelmente. Por mais saliva que se gaste na questão do que as crianças devem ou não assistir, o problema real é o que a geração dos pais quer que seja mostrado. Enquanto houver demanda, a indústria pornô estará ali para servi-la. Enquanto houver cigarros, as crianças fumarão. Enquanto papai guardar revistas de mulher pelada e vídeos pornôs na gaveta das meias, seus rebentos vão vê-los. A idéia de que as crianças podem existir num mundo e seus pais noutro é uma ilusão. Histórica e etimologicamente, a pornografia é tão-somente a publicidade da prostituição. Ela é distinta, portanto, da obscenidade. Obscenidade é a descrição do que não pode ser visto. Alguma pornografia, mas de modo algum 
toda, é obscena: boa parte da obscenidade não é minimamente pornográfica. (...) Boa parte da pornografia abastece nichos de mercado e é absolutamente irrelevante para as pessoas cuja sexualidade não foi desviada nessa direção. As preferências de minorias sexuais são classificadas, em geral, como parafilias e consideradas anormais; a sociedade permissiva tendia a aceitar as parafilias como um aspecto essencial da atividade sexual humana. "Aquilo que ligar você" era o que você estava autorizado a fazer nos inocentes anos 60 , antes de a tampa ser levantada e termos uma visão da lata de vermes que é a sexualidade humana. O que os reformadores sexuais dos anos 60 pensavam estar liberando era o desejo das pessoas de agradarem umas às outras; o que eles não estavam preparados para enfrentar foi a intensidade da necessidade que muitas pessoas têm de machucar umas as outras e inclusive ferir, para chegar mais perto de seu próprio orgasmo total. (...) Numa sociedade sem liberdade, a maioria das atividades chamadas consensuais representa a capitulação do que não tem poder às exigências do poderoso. O poder vem em diversos disfarces, como dinheiro, status, patriarcalismo e invulnerabilidade emocional. O propósito da pornografia é despertar desejo na ausência deste, despertar apetite onde não existe fome (...) Onde existe necessidade, não é preciso estimular a demanda; onde não existe qualquer necessidade, uma imagem sedutora terá de ser usada para criar a demanda. As pessoas que não têm o menor desejo de comer um pedaço de pão com manteiga porque não estão com fome, podem ser estimuladas a desejar chocolate se o chocolate lhes for apresentado como algo mais que comida, como êxtase, exultação e orgasmo. O chocolate é uma guloseima que engorda, comercializada como se fosse uma droga; quando os alimentos, de tortas de maçã a queijos processados, são apresentados como causadores de euforia, é a experiência da droga apresentada como meio para o bem-estar. O alimento produzido comercialmente é também falso, quase sempre não produzidos com as substâncias mencionadas no rótulo, mas com químicos análogos e aditivos, e incrementados com aditivos aromáticos e quantidades exageradas de sal e adoçantes. Da mesma forma, o sexo rápido comercial é falso, divorciado da paixão e da reprodução. A propaganda de alimentos vende comida de fantasia e a de sexo, sexo de fantasia. Do mesmo jeito que a publicidade de fast-food e doces eliminou o apetite de tal forma que ninguém sabe agora que a fome é o melhor tempero para qualquer comida, a pornografia eliminou o desejo. O marketing de alimentos nos trouxe distúrbios alimentares e é bem provável que o marketing do sexo terá as mesmas conseqüências. Já nos empanturramos ou morremos de fome por sexo de tal forma que fazer amor virou atividade substitutiva - fetichista, obsessivo-compulsiva e profundamente sem graça. (...) A pornografia desencadeia uma reação genital, provoca excitação e sugere uma descarga iminente; a pornografia é o que torna o sexo rápido possível, sozinho ou acompanhado. O fast-food é um meio de neutralizar a fome e, portanto, da intrusão de imagens de alimentos em outras ocupações mentais. O sexo rápido também deveria preparar o terreno para um tipo 
diferente de ação. A disseminação da pornografia é muito parecida com a ascensão da batata chips que agora ocupa dois lados inteiros de um corredor do supermercado local. Agora as fritas vêm temperadas, e também embebidas de produtos químicos que simulam sabores de camarão, bacon defumado, molho inglês... (...) As fritas são um excelente exemplo de alimento que engorda e não alimenta; o sexo virtual, como a comida virtual, é planejado para deixar o consumidor insatisfeito. A discussão do que pode ou não ser visto em vídeos e filmes não têm nada a ver com pornografia e sim com limiares de capacidade de chocar, que recuam sem parar. (...) Durante quase 70 anos, o movimento avançou na direção de mostrar mais; o que deveríamos esperar, mais cedo ou mais tarde, é que o estômago da sociedade fique virado, já que houve todo tipo de práticas, das brigas de cães e de galos, saunas gays e sex shops à queima de livros, prisão de desviados, véus cobrindo mulheres e raspagem da cabeça de homens. O Taliban não é nenhum fenômeno novo; o que deveríamos almejar, talvez, seria por uma revolução mais pacífica e menos cruel, em que as pessoas ficassem longe de espetáculos indecentes e brutais simplesmente por não ter estômago para eles, e seus promotores começassem a perder muito dinheiro.

Jimena Pettinato (PETTINATO, 2001) mostra como funciona a pornografia na Internet:

Onde começou esta estória? Qualquer pessoa com uma câmara e uma mente um pouco perversa pode criar uma imagem para este tipo de site. A pornografia de amateurs é bastante comum, mas as maiorias dos sites que tratam estes temas são profissionais. Felizmente para os que se dedicam a este tipo de negócios, não faltam pessoas que posem frente a uma câmara e tirem a roupa. Os fotógrafos com conexões na tradicional indústria sabem onde localizar os modelos que começam a se apresentar nas páginas Web com a intenção de se fazerem conhecer para depois serem convocados para filmes ou revistas. Mas ainda assim é um negócio legítimo, cada modelo deve ser maior de idade e confirmar aos fotógrafos, os direitos de vender suas imagens. Nos últimos dois anos, a regulação segura tem-se convertido numa realidade aceitada, e a maioria dos fotógrafos não se arrisca a vender seus produtos sem a devida autorização. Uma vez que o material está pronto deve-se fazê-lo chegar até aquelas pessoas que desejam publicá-lo on-line. Quando a Rede era algo recente e desconhecido, muitas pessoas simplesmente escaneavam fotografias de algumas revistas especiais, ou as apresentações dos vídeos pornográficos, e depois as publicavam em grupos de debate. Assim começaram a formar-se os primeiros sites pornográficos com material copiado de um site a outro. (...) Alguns fotógrafos vendem diretamente seu material a este tipo de site. Porém geralmente este processo tem duas partes: Um distribuidor compra pornografia de um grande número de fontes originais, e depois revende as imagens aos proprietários dos sites. A maior parte das fotografias são digitalizadas, escaneadas, e depois armaze- 
nadas em CD-ROMs. Cada CD contém ao redor de 600 imagens e pode ser vendido por diferentes preços, segundo o tipo do material que seja. (...) Com tanta pornografia gratuita disponível, os sites pagos devem exibir algo mais que simples imagens. Os vídeos interativos, as atuações das celebridades, e imagens de famosas personagens, têm um alto custo de produção, e ademais pode ser uma diversão não muito produtiva para os consumidores. Por isto, a maior parte do material pago é distribuído pelas mesmas companhias que os desenvolvem. (...) Aproximadamente umas 30 milhões de pessoas por dia entram nos sites pornográficos, e provavelmente, naqueles que oferecem imagens gratuitas. De acordo às estatísticas, os sites que oferecem material gratuito compreendem entre 70 e $80 \%$ do material pornográfico disponível. Estes sites são os que verdadeiramente atrapalham aqueles nos quais se deve pagar para obter informação. Os sites de pornografia gratuita só ganham dinheiro quando um usuário visita o site do anunciante e realiza uma compra. Geralmente, um site "premium" partilha entre 30 e $60 \%$ de cada venda com o site ao qual se refere. $\mathrm{E}$ ainda que esta cifra lhe pareça bastante generosa, deve pensar que atualmente é difícil os sites gratuitos capitalizarem seus acordos. Ainda que o 5 ou o $10 \%$ dos visitantes poderiam clicar sobre um banner, só um ou dois de cada mil usuários comprará o serviço oferecido. Por isto, os sites gratuitos utilizam alguns truques para atrair a maioria dos usuários para que cliquem sobre seus banners e assim possam ganhar dinheiro; como por exemplo, prometer mais conteúdo gratuito, e exibir mais anúncios cada vez que um usuário deixar a página. Geralmente, os usuários não se importam com a utilização de determinados truques para chamar a atenção, desde que haja suficiente material gratuito para satisfazer suas necessidades. A última palavra é do usuário, que realmente decide se o material que encontra nos sites gratuitos satisfaz todas suas necessidades. De repente, algum dia decide clicar sobre alguns dos banners dos sites não gratuitos, registrar-se, e começar a pagar... O conteúdo dos sites pornográficos pagos, particularmente os vídeos ao vivo e os chats interativos, são extremamente custosos de produzir, e a maioria dos sites pagos compram seu material de centenas de fornecedores que o oferecem. Para poder pagar este material, os sites necessitam não só atrair, mas também manter a milhares de usuários que contratem seus serviços. Uma vez que o cliente se registra, é muito importante que se mantenha sua atenção e sua visita durante alguns meses. Os sites pornográficos pagos oferecem o mesmo tipo de incentivo, ou seja, preços mais baratos durante um período determinado de tempo, tratos especiais, desconto para o registro de algum amigo etc., igual que outras empresas que assim o fazem também na base dos registros. (...) Alguns prometem um mês grátis de acesso, mas finalmente, o usuário termina pagando. (...).

Carlos Alberto Di Franco (DI FRANCO, 2001) diz o seguinte sobre Internet e pornografia: 
(...) Os problemas levantados pelo mau uso da Internet, são infinitamente menores que os benefícios trazidos por esse fascinante canal de aproximação dos povos, de democratização dos conhecimentos e de globalização da solidariedade. Seus desvios não serão resolvidos por meio de tutelas governamentais. Na verdade, a Internet salienta uma nova realidade: chegou para todos, sobretudo para a família, a hora da liberdade e da responsabilidade. Se a família não cumprir o seu papel, não será o paternalismo do governo que preencherá esse espaço com a devida competência. Não há regulamento capaz de suprir a ausência da família. A educação para o exercício da liberdade é o grande desafio dos nossos dias. Como salientou matéria do The Economist, 'ao atingir tantas pessoas, com tanta facilidade, a Internet pode resultar, ironicamente, em que as pessoas precisem menos dos governos, à medida que coloca a tecnologia nas mãos de quem a quiser. Os crivos contra a pornografia não são perfeitos, mas são menos permeáveis do que os toscos instrumentos brandidos pelos censores do governo'. A aventura da liberdade, desguarnecida de ilusórias intervenções do Estado, acabará gerando uma sociedade mais consciente e amadurecida.

\section{3 - Pornografia Infantil e Pedofilia}

A pornografia é um meio de expressão que tem sua liberdade garantida como outro qualquer, desde que não se seja ou não se torne ilegal, como no caso do envolvimento de crianças ou o material ser vendido a menores.

A pornografia infantil é a maior preocupação dentro e fora da Internet, não apenas sobre veiculação de imagens de crianças em cenas de sexo, mas principalmente a exploração de crianças para elaboração dessas imagens.

Uma contradição dos novos tempos: a cultura de massa exalta a sexualidade infantil enquanto os pedófilos são demonizados (ADAMS, 2002).

A Interpol define pornografia infantil como a consequêencia da exploração ou abuso sexual perpetrado contra a criança, podendo ser caracterizado como qualquer meio de representar ou promover o abuso sexual de uma criança, inclusive impresso e/ou gravado, focalizando atos sexuais ou órgãos sexuais de crianças (MAUR, 1999).

Importante a diferenciação entre a pedofilia e a exploração sexual. Na pedofilia, o pedófilo seduz a criança para si próprio. Na exploração, crianças são aliciadas para serem exploradas sexualmente por terceiros (HAIDAR, 2001).

Hélia Barbosa (BARBOSA, 1999) define abuso sexual como a utilização para fins sexuais do corpo de uma criança ou adolescente, por parte de um adulto, caracterizando-se pelo não consentimento da vítima, que é coagida física, emocional ou psicologicamente. É uma relação bilateral para satisfação unilateral do abusador, compreendendo desde atos libidinosos até o estupro. A autora define ainda exploração comercial da sexualidade infantil como a prática de sexo com criança ou adolescente, mediante o comércio de seus corpos através de meios coercitivos ou 
persuasivos, caracterizados como transgressão a seus direitos e à liberdade individual. A exploração comercial da sexualidade é praticada para oferecer satisfação e prazer unilateral ao cliente, assim como para proporcionar ganhos econômicos ao intermediador. É uma atividade sistêmica, triangular e criminosa.

Patrice Dunaigre (DUNAIGRE, 1999) define pedofilia como manifestações e práticas de desejo sexual que alguns adultos desenvolvem em relação a crianças de ambos os sexos na pré-puberdade. Para o autor, sua origem está na proibição do incesto e na instituição de um sistema de parentesco. Esses elementos formam a identidade da criança dentro de uma estrutura codificada. Com isso a criança passa a ter um status social específico. O autor destaca o tom usado pela mídia nas coberturas sobre abuso sexual, nas quais se acusa o agressor adulto - o pedófilo -... e a incompetência e negligência dos responsáveis pela criança e das autoridades. A vítima - a criança - fica reduzida a objeto do ato cometido. E a mídia assume o papel de seu porta-voz. Demoniza-se o agressor ao mesmo tempo em que se infantiliza a vítima. Mantém-se o estereótipo da criança inconseqüente, irresponsável, um mero objeto de poder ou desejo, uma superfície unidimensional sobre a qual pode ser projetado todo tipo de fantasia.

Ficou famoso no Brasil um caso de estupro no qual o suposto agressor foi absolvido no Supremo Tribunal Federal, quando o juiz alegou na sentença que devido ao acesso que o jovem tem à informação, não haveria mais meninas de doze anos, mas sim moças. A menina disse no processo que sabia o que estava fazendo e queria manter relações sexuais com o suposto agressor.

Sobre o comportamento pedófilo, Patrice Dunaigre explica que há uma distinção entre o tipo exclusivo - aquele sexualmente atraído por crianças - e o não-exclusivo - aquele que também é ativo com adultos. Esses comportamentos variam do exibicionismo sem contato físico até atos de penetração, visando ou não às zonas sexuais. Numa classificação, ainda segundo o mesmo autor, temos a pedofilia de situação, quando adultos - geralmente com personalidade patológica - atacam crianças sem necessariamente sentirem atração sexual por elas. $\mathrm{E}$ a forma convencional, a pedofilia preferencial, que envolve um desvio sexual visando crianças na pré-puberdade (treze anos ou menos) e é cometido de várias formas, segundo diversos critérios, entre os quais: preferência sexual, tipo de violação sexual, estratégias usadas, formas de penetração, traços de caráter, competências sociais fracas ou fortes, etc.

Segundo Leandro Sarmatz (SARMATZ, 2002), a OMS define pedofilia como a ocorrência de práticas sexuais entre um indivíduo maior de dezesseis anos com uma criança em pré-puberdade (treze anos ou menos). Para o pedófilo a criança é um objeto, não um parceiro. A maioria dos pedófilos tem entre 30 e 45 anos, sendo 95\% do sexo masculino. Embora não sejam em sua maioria homossexuais, $71 \%$ preferem meninos. Proteção e dominação constituem os pilares básicos da pedofilia. Ainda segundo o autor, à medida que amadurecem, homens procuram pessoas mais jovens por causa de insegurança psicológicas, inclusive em relação ao tamanho e desempenho do pênis. $O$ sexo com menores seria a forma de afirmar sua própria 
segurança. A psicanálise define pedofilia como uma perversão sexual, não como doença, mas como uma parafilia ${ }^{2}$.

Gianni Carta (CARTA, 2001) mostra que a pedofilia é facilitada pela miséria, turismo sexual e pela Internet, tornando-se uma lucrativa indústria. Não afeta apenas países pobres como Tailândia, Camboja e Costa Rica - considerada o paraíso da pedofilia, pois não considera crime a posse de pornografia infantil - mas também países ricos como Estados Unidos e Bélgica, os quais, através da cooperação entre suas polícias, na chamada Operação Catedral, acabaram com uma das maiores redes internacionais de pedofilia, o clube virtual Wonderland. Diz o autor:

O abuso sexual contra crianças é uma das mais lucrativas indústrias globais. Dados levantados pelo juiz Walter Fanganiello Maierovitch - e apresentados por ele na Itália, em dezembro de 2000 , durante a convenção da ONU sobre crime organizado transnacional - mostram a dimensão do mercado internacional da pedofilia. Segundo Maierovitch, o lucro anual com a pedofilia chega a US $\$ 5$ bilhões. Vídeos envolvendo crianças rendem um lucro anual de US $\$ 280$ milhões. E, ainda de acordo com o juiz, no ano passado foram localizados 7750 sites de pedofilia na Internet - 50\% deles nos EUA - a previsão de especialistas é que o número total de sites do gênero deve ser cerca de dez vezes maiores que esse. "Aproximadamente, 2 milhões de crianças são cooptadas e escravizadas pelas internacionais criminosas", afirma Maierovitch. Como em todos os tipos de comércio, a indústria da pedofilia existe porque há demanda. E nos últimos anos, a exploração sexual de menores vem crescendo. Devido aos preços cada vez mais baixos das passagens aéreas e dos pacotes turísticos, viajantes pedófilos, em sua maior parte norte-americanos e europeus, vão com maior frequiência a países na Ásia, África e América Latina. E com a introdução da Internet, a rede global de pedófilos ganhou força. Cresceu o fluxo de informações sobre crianças em diversos países, e também a comercialização de fotografias e vídeos pornográficos. (...) O psiquiatra francês Pierre Sabourin diz que o pedófilo, quase sempre homem, pode ter qualquer idade, orientação sexual, religião e nacionalidade. Muitas vezes sofreu abuso sexual na infância. Tende a viver só, a não ter emprego, e tem dificuldade em fazer amizade com adultos. $\mathrm{O}$ que explica o fato de ele se sentir à vontade com crianças. Segundo o site da Interpol, o pedófilo predador, aquele que rapta e estupra, é a exceção, não a regra. O mais comum é o pedófilo que compra pornografia infantil e não realiza suas fantasias. Forças inibidoras internas, diz ainda a Interpol,

2 O Dicionário Aurélio define parafilia como "cada um de um grupo de distúrbios psicossexuais em que o individuo sente necessidade imediata, repetida e imperiosa de ter atividades sexuais, em que se incluem, por vezes, fantasias com objeto não humano, auto-sofrimento ou auto-humilhaçāo, ou sofrimento ou humilhação, consentidos ou não, de parceiro. [Deste grupo fazem parte o exibicionismo, o fetichismo, a frottage, a pedofilia, o masoquismo sexual, o sadismo sexual e o voyeurismo. J". 
controlam seus impulsos. E forças inibidoras externas (medo de ser pego, encarcerado, e de ser exposto publicamente) contribuem para que o pedófilo não moleste crianças. Porém, o tédio e o estresse podem desencadear um novo ciclo. O pedófilo passa, então, a ir a lugares públicos, como piscinas, ou parques frequientados por crianças. Ele detecta aquelas que lhe parecem mais vulneráveis, talvez tímidas, e faz contato. Oferece presentes, quem sabe um passeio de automóvel. As táticas são várias. O processo de aproximação entre pedófilo e presa pode levar anos. Em certos casos, nunca haverá contato sexual. Mas, quando e se ocorre o ato sexual, o pedófilo usa artifícios para que a criança não conte nada a ninguém: ameaças, favores, sentimento de culpa. (...) Membros de sofisticados clubes de internautas globais, como o Wonderland, que envolveu 13 países e 180 homens, trocaram, até serem descobertos no início do ano, imagens de 1.236 vítimas, todas menores. Em várias ocasiões, crianças foram estupradas ao vivo, via Internet. Como combater a pedofilia na Internet? Parcerias como aquela entre a polícia belga e a americana. Em março, 30 pessoas que distribuíam imagens pornográficas de crianças foram presas em Manchester, graças à colaboração entre a polícia e a empresa privada SurfControl.

O Estatuto da Criança e do Adolescente determina:

Art. 241 - Fotografar ou publicar cena de sexo explícito ou pornográfica envolvendo criança ou adolescente: Pena - reclusão de um a quatro anos.

Sobre essa conduta há um julgamento do Supremo Tribunal Federal:

BRASIL. Supremo Tribunal Federal, Habeas Corpus - 76689/PB, Primeira Turma, Relator: Ministro Sepúlveda Pertence, 22.09.98. "Crime de Computador": publicação de cena de sexo infanto-juvenil (E.C.A., art. 241), mediante inserção em rede BBS/Internet de computadores, atribuída a menores: tipicidade: prova pericial necessária à demonstração da autoria: HC deferido em parte. 1. O tipo cogitado - na modalidade de "publicar cena de sexo explícito ou pornográfica envolvendo criança ou adolescente" ao contrário do que sucede, por exemplo, aos da Lei de Imprensa, no tocante ao processo da publicação incriminada é uma norma aberta: basta-lhe à realização do núcleo da ação punível a idoneidade técnica do veículo utilizado à difusão da imagem para número indeterminado de pessoas, que parece indiscutível na inserção de fotos obscenas em rede BBS/Internet de computador. 2. Não se trata no caso, pois, de colmatar lacuna da lei incriminadora por analogia: uma vez que se compreenda na decisão típica da conduta criminada, o meio técnico empregado para realizá-la pode até ser de invenção posterior à edição da lei penal: a invenção da pólvora não reclamou redefinição do homicídio para tornar explícito que nela se compreendia a morte dada a outrem mediante arma de fogo. 3 . Se a solução da controvérsia 
de fato sobre a autoria da inserção incriminada pende de informações técnicas de telemática que ainda pairam acima do conhecimento do homem comum, impøe-se a realização de prova pericial.

O Estatuto foi criado em 1990 quando se pensava apenas em publicação impressa ou vídeo. Agora com as mídias digitais isto precisa ser revisto para que não haja dúvida quanto à aplicação do Estatuto. Organizações não-governamentais e autoridades têm criticado este artigo por causa da pena muito branda. Mas não é esse o caminho.

\section{Conclusão}

É preciso observar os dois núcleos do tipo previsto no artigo 241 do ECA. Foram igualadas duas condutas de natureza distinta. Enquanto fotografar pressupõe a exploração sexual do menor, pois será a realização efetiva do ato, requerendo toda uma preparaçlo para a elaboração da fotografia, portanto uma conduta muito mais grave, publicar consiste apenas em tornar público algo já realizado, disponibilizar a cena pornografica. Nem sempre quem publica é o mesmo que fotografa. Na maior parte das vezes, aquele que publica ou transaciona fotos utiliza material produzido por terceiros.

Não se pode reduzir a conduta pedófila ao ato em si. Deve-se observar todo o contexto social. Mas também não se pode afastar a dimensão penal, pois há violência praticada. O pedófilo precisa primeiramente de tratamento, não de cadeia. Muitas vezes, a prática daquela conduta para o indivíduo se torna inevitável, irresistível, embora saiba que seja errado, tenha consciência de seu ato. Há que se pensar em tornar o tratamento para o pedófilo obrigatório, como já se faz em alguns países.

$O$ objetivo deve ser a repressão à produção do material, quando se pratica o dano efetivo ao menor.

As duas condutas devem ser reprimidas. Mas o simples aumento de pena não

é a solução. É preciso separar as condutas buscando uma punição conforme a gravidade de cada ação. Na maioria dos casos são punidos da mesma forma aquele que abusou para elaboração de fotos e aquele que apenas transacionou, trocou fotos pela Internet.

\section{Referências Bibliográficas}

ADAMS, Tim. $O$ karaokê do sexo. Carta Capital. São Paulo, n 214, pp. 12-17, 6 de novembro 2002.

AVANCINI, Marta. Internet representa 43\% das denúncias levadas a Ministério. O Estado de São Paulo. São Paulo, 15 de maio 2002. Cidades, p. C-1.

BARBOSA, Hélia. Abuso e Exploração Sexual de crianças: origens, causas, prevenção e atendimento no Brasil. In: UNESCO. Inocência em Perigo - Abuso 
sexual de crianças, pornografia infantil e pedofilia na Internet. Rio de Janeiro: Garamond, 1999. Capítulo 2, pp. 24-41.

BORGES, Robinson. Um desejo obscuro pelo objeto. Valor Econômico. São Paulo, 1 de dezembro 2000. Caderno Eu\&, pp. 12-13.

BRASIL. Supremo Tribunal Federal, Recurso em Mandado de Segurança: RMS18534, Segunda Turma, Relator: Ministro Aliomar Baleeiro, 1/10/1968.

CARTA, Gianni. Mercado brutal. Carta Capital. São Paulo, edição 156, pp. 14-19, 12 de setembro 2001.

COMIM, Arnaldo. TVs vivem 'inferno astral' por causa de decisões judiciais. Valor Econômico. São Paulo, 17 de novembro 2000. Empresas \& Tecnologia, p. B-3. DI FRANCO, Carlos Alberto. Internet e Pornografia. Revista Eletrônica Mirandum, no endereço http://www.hottopos.com/mirand3/internet.htm, setembro-dezembro 1997. Acessado em 2001.

DUNAIGRE, Patrice. O ato pedófilo na história da sexualidade humana. In: UNESCO. Inocência em perigo - Abuso sexual de crianças, pornografia infantil e pedofilia na Internet. Rio de Janeiro: Garamond, 1999. Capítulo 1, pp. 9-23.

EYSENCK, Hans Jurgen. Usos e abusos de pornografia. In: EYSENCK, H.J.. Sexo, Pornografia, Personalidade - Consequiências sociais da Psicologia moderna. São Paulo: Ibrasa, 1976.

GARBIN, Luciana. Campanha combate silêncio sobre abuso infantil. O Estado de São Paulo. São Paulo, 15 de maio 2002. Cidades, p. C-1.

GREER, Germaine. O mercado do sexo. Carta Capital. São Paulo, $n^{\circ} 135$, pp. 50-52, 8 de novembro 2000.

HAIDAR, Rodrigo. Impunidade e indiferença. In: CARTA, Gianni. Mercado Brutal. Carta Capital. São Paulo, edição 156, p. 18-19, 12 de setembro 2001.

MAIEROVITCH, Walter. Os negócios do sexo. Carta Capital. São Paulo, n 218 , pp. 12-16, 4 de dezembro 2002.

MANDL, Carolina. Aumentam os relatos de pedofilia. Folha de São Paulo. São Paulo, 15 de maio 2002. Informática, p. F-3.

MARZOCHI, Marcelo De Luca. Direito.Br - Aspectos Jurídicos da Internet no Brasil. São Paulo: LTR, 2000.

MAUR, Agnès Fournier de Saint. Abuso Sexual de crianças na Internet: um novo desafio para a Interpol. In: UNESCO. Inocência em Perigo - Abuso sexual de crianças, pornografia infantil e pedofilia na Internet. Rio de Janeiro: Garamond, 1999. Capítulo 9, pp. 102-109.

MIGLIACCIO, Marcelo. A mulher que as meninas vêem na TV. O Estado de São Paulo. São Paulo, 20 de janeiro 2001. Caderno 2, p. D-10.

MORAES, Eliane Robert e LAPEIZ, Sandra Maria. O que é Pornografia? São Paulo: Abril Cultural e Brasiliense. Coleção Primeiros Passos, 1985.

NORDLAND, Rod e BARTHOLET, Jeffrey. The Web's dark secret. Newsweek. New York, 19 de março 2001, pp. 36-43.

NOVAES, Carlos Eduardo e LOBO, César. Sexo para principiantes. São Paulo: Ática, $4^{\circ}$ edição, 1997. 
PETTINATO, Jimena. Sexo em la Red, agosto de 2000, no endereço http://www.omicro.com.br/artigos/sexoenweb2/index.php3. Acessado em 2001.

SARMATZ, Leandro. Inocência roubada. Super Interessante. São Paulo, edição 176, pp. 39-46, maio 2002.

VIEIRA, Ana Luísa. No Brasil, "mão-de-obra" não falta. In: MAIEROVITCH, Walter. Os negócios do sexo. Carta Capital. São Paulo, $n^{\circ} 218$, p. 15, 4 de dezembro 2002.

WERNECK, Felipe. Globo corta dez minutos de "Laços de Família". O Estado de São Paulo. São Paulo, 16 de novembro 2000. Geral, p. A-24. Juiz acusa novela e critica promotores de SP. O Estado de São Paulo. São Paulo, 17 de novembro 2000. Geral, p. A-11. 


\section{Direito Internacional dos Refugiados}

José H. Fischel de Andrade

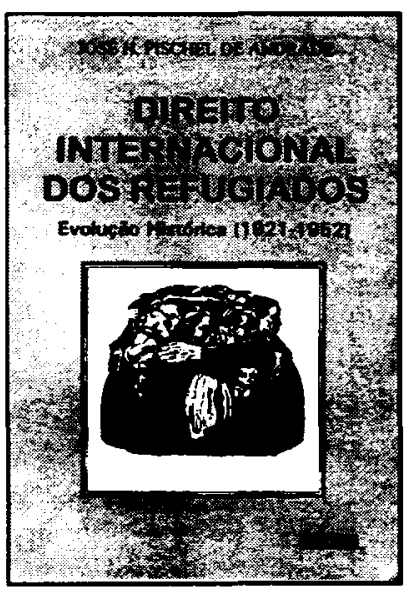

É vista aqui a fase histórica do Direito Internacional dos Refugiados (de 1921 a 1952). O Autor aborda a agenda internacional, a evolução das relaçōes internacionais e os fatores políticos, sociais e juridicos que influenciaram as decisōes tomadas em nivel intergovernamental e que repercutiram na proteção brindada aos perseguidos. São minuciosamente estudados os instrumentos jurídicos concertados, com suas distintas definições do que se deveria entender por "refugiado", e as organizaçōes internacionais criadas com vistas à proteção dos refugiados pela comunidade internacional.

Ref. $0103 \quad$ Brochura 228 págs.

\section{Direito Societário e Mercado de Capitais}

\section{Luiz Leonardo Cantidiano}

Fruto de sua experiência profissional, o autor analisa questōes relacionadas às sociedades anônimas e ao mercado de capitais, com que empresários e consultores vêm se defrontando na atual fase do processo de desenvolvimento do país. São abordadas aqui as particularidades que decorrem da alienação do controle de uma companhia, especialmente se aberta. São apontadas também as relaçōes existentes entre o programa de privatização das empresas estatais e o mercado de capitais.

Ref. 0100

Form. 14x21

Brochura 1996

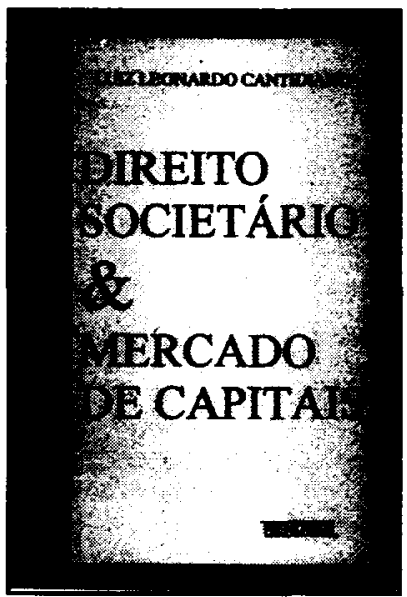

